\title{
REVIEW
}

\section{Obstructive sleep apnoea/hypopnoea syndrome: relationship with obesity and management in obese patients}

\author{
La sindrome da apnee notturne: correlazione con l'obesità e gestione del paziente \\ obeso
}

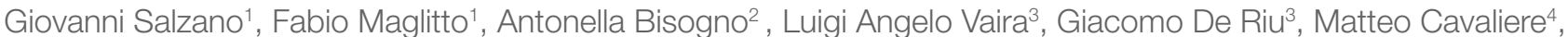
Arianna di Stadio ${ }^{5}$, Massimo Mesolella ${ }^{6}$, Gaetano Mottaํ, Franco Ionna1, Luigi Califano ${ }^{8}$, Francesco Antonio Salzano

${ }^{1}$ Maxillo-Facial and ENT Surgery Unit, INT- IRCCS "Fondazione G. Pascale", Naples, Italy; ${ }^{2}$ Department of Medicine, Surgery and Dentistry, "Scuola Medica Salernitana", University of Salerno, Baronissi (Salerno), Italy; ${ }^{3}$ Maxillofacial Surgery Unit, University Hospital of Sassari, Sassari, Italy; ${ }^{4}$ Department of Otolarhinolaryngology, University Hospital "San Giovanni di Dio e Ruggi d'Aragona", Fisciano, Salerno, Italy; ${ }^{5}$ Otolaryngology Department, University of Perugia, Perugia, Italy; ${ }^{6}$ Department of Neuroscience, Reproductive and Odontostomatological Science, Ear Nose and Throat Unit, University of Naples "Federico II", Naples, Italy; ${ }^{7}$ Clinic of Otorhinolaryngology, Head and Neck Surgery Unit, Department of Anesthesiology, Surgical and Emergency Science, University of Campania "Luigi Vanvitelli", Naples, Italy; ${ }^{8}$ Maxillofacial Surgery Unit, Department of Neurosciences, Reproductive and Odontostomatological Sciences, University Federico II, Naples, Italy
\end{abstract}

\section{SUMMARY}

Obstructive sleep apnoea/hypopnoea syndrome (OSAHS) is a disease characterised by upper airway obstruction during sleep, quite frequent in the general population, even if underestimated. Snoring, sleep apnoea and diurnal hypersomnia are common in these patients. Central obesity plays a key role: it reduces the size and changes the conformation of the upper airways, besides preventing lung expansion, with consequent reduction of lung volumes. Furthermore, obese people are also resistant to leptin, which physiologically stimulates ventilation; as a result, this causes scarce awakening during apnoea. OSAHS diagnosis is based on the combination of clinical parameters, such as apnoea/hypopnoea index (AHI), medical history, physical examination and Mallampati score. The first objective reference method to identify OSAHS is polysomnography followed by sleep endoscopy. Therapy provides in the first instance reduction of body weight, followed by continuous positive airway pressure (CPAP), which still remains the treatment of choice in most patients, mandibular advancement devices (MAD) and finally otolaryngology or maxillofacial surgery. Among surgical techniques, central is barbed reposition pharyngoplasty (BRP), used in the field of multilevel surgery.

KEY WORDS: OSAHS, obesity, CPAP, pharyngoplasty, orthognatic surgery

\section{RIASSUNTO}

La sindrome da apnee notturne è una malattia caratterizzata da ostruzione delle vie aeree superiori durante il sonno, abbastanza frequente nella popolazione generale, anche se sottovalutata. Russamenti, apnee notturne e ipersonnia diurna sono comuni in questi pazienti. L'obesità svolge un ruolo chiave: riduce le dimensioni e modifica la conformazione delle vie aeree superiori, oltre a prevenire l'espansione polmonare, con conseguente riduzione dei volumi polmonari. Le persone obese sono anche resistenti alla leptina, che stimola fisiologicamente la ventilazione; di conseguenza, questo provoca uno scarso risveglio durante l'apnea. La diagnosi si basa sulla combinazione di parametri clinici, come indice di apnea / ipopnea (AHI), anamnesi, valutazione clinica e Mallampati score. La prima indagine strumentale per identificare pazienti OSAHS è la polisonnografia seguita dalla sleep endoscopy. La terapia prevede in primo luogo la riduzione del peso corporeo, seguita dalla ventilazione a pressione positiva continua delle vie aeree $(C P A P)$, che rimane ancora ad oggi il trattamento di scelta nella maggior parte dei pazienti, dispositivi di avanzamento mandibolare $(M A D)$ e infine diversi approcci chirurgici. Tra le tecniche chirurgiche la faringoplastica (BRP), rappresenta la tecnica prescelta.

PAROLE CHIAVE: OSAHS, obesità, CPAP, faringoplastica, chirurgia ortognatica
Received: September 1, 2020

Accepted: December 28, 2020

Correspondence

Fabio Maglitto

Maxillo-Facial and ENT Surgery Unit, INT-IRCCS

"Fondazione G. Pascale", Naples, Italy

Tel. +39081 5903384. Fax +390815903461

E-mail: fmaglitto@gmail.com

Funding

None.

Conflict of interest

The Authors declare no conflict of interest.

How to cite this article: Salzano G, Maglitto F, Bisogno A, et al. Obstructive sleep apnoea/ hypopnoea syndrome: relationship with obesity and management in obese patient. Acta Otorhinolaryngol Ital 2021;41:120-130. https://doi. org/10.14639/0392-100X-N1100

() Società Italiana di Otorinolaringoiatria e Chirurgia Cervico-Facciale

\section{(c) (1) $(2)$}

This is an open access article distributed in accordance with the CC-BY-NC-ND (Creative Commons Attribution-NonCommercial-NoDerivatives 4.0 International) license. The article can be used by giving appropriate credit and mentioning the license, but only for non-commercial purposes and only in the original version. For further information: https:// creativecommons.org/licenses/by-nc-nd/4.0/deed.en 


\section{Introduction}

Obstructive sleep apnoea/hypopnoea syndrome, also known as OSAHS, is a disease characterised by intermittent and repeated episodes of complete or partial upper airway obstruction during sleep: these episodes are more than five per hour and are usually associated with recurrent oxyhaemoglobin desaturations, sympathetic hyperactivity and variation of intrathoracic pressures, which eventually lead to sleep fragmentation, tiredness and excessive diurnal sleepiness ${ }^{1,2}$.

As demonstrated by several epidemiologic studies, OSAHS is a fairly common condition in the general population, with a prevalence of $24 \%$ in men and $9 \%$ in women aged between 30 and 60 years; in the paediatric population, OSAHS may appear at all ages, from neonatal to adolescence, with an estimated prevalence included between 2 and $5.7 \%$. However, despite this frequency, OSAHS is an under-reported condition, identified only in $5-10 \%$ of affected subjects ${ }^{3-5}$.

OSAHS symptomatology is dominated by snoring, in addition to frequent awakenings, choking, disrupted sleep and insomnia ${ }^{6}$ and to a lesser extent nocturia ${ }^{7}$. Chronic fatigue, daytime sleepiness and hypersomnia, secondary to sleep fragmentation, are the most significant diurnal symptoms ${ }^{1}$, which are potentially disabling and dangerous: in fact, excessive diurnal sleepiness represents a significant cause of motor vehicle crashes, which in OSAHS population are two-fold and up to seven-fold greater than a control population ${ }^{8}$.

Although all these symptoms affect the quality of life, the clinical relevance of OSAHS is mainly due to its strong association with hypertension, metabolic syndrome, diabetes, heart failure, coronary artery disease, arrhythmias, stroke, pulmonary hypertension ${ }^{9}$, neurocognitive disorders, especially those regarding attention and concentration domains ${ }^{10}$, and mental disorders, such as depression and anxiety.

All OSAHS symptoms are due to the pharyngeal muscles hypotonia, especially during REM sleep ${ }^{11}$, which is the cause of an initial subobstruction with increased resistance of upper airways, responsible for hypopnoea and snoring; at a later time the obstruction turns complete, with respiratory airflow arrest and therefore obstructive apnoea ${ }^{12}$.

The airflow obstruction becomes clinically relevant if anatomic or neuromuscular factors acting on pharynx are present ${ }^{13}$ : accordingly, risk factors in the onset of OSAHS are all anatomical conditions that reduce the calibre of upper airways, such as septum deviation, nasal polyps, turbinate, adenotonsillar and lingual tonsil hypertrophy, tumours, retrognathia and inferior displacement of the hyoid bone ${ }^{14-16}$, but also obesity ${ }^{17}$. On the other hand, neuromuscular factors can also cause airway obstruction in OSAHS: among them, sleeping in the supine position, which facilitates the occurrence of apnoea because of posterior repositioning of the tongue by gravitational effect ${ }^{18}$, and alcohol and smoking, which promote relaxation of airway muscles ${ }^{19}$.

In this pathophysiological context, however, particular attention must be paid to obesity, about which this review is concerned.

\section{The interactions between OSAHS and obesity}

Nowadays obesity is widely recognised as the most important risk factor for OSAHS: a 10\% weight gain increases the risk of developing this disease by six-times ${ }^{20}$ and according to recent estimates more than half of obese people are affected by OSAHS ${ }^{4}$. Particularly at risk are people affected by central or visceral obesity, with prevalent fat deposition in the trunk and neck area, also known as android obesity, because typically male ${ }^{21}$.

The higher prevalence of OSAHS in obese subjects is not limited to adults, but also to children and adolescents: in fact, obese children have a $46 \%$ prevalence of OSAHS ${ }^{22}$, a finding further aggravated by the obesity epidemic in paediatric age ${ }^{23}$. In turn, children and adolescents with OSA have more than a six-fold increased risk of metabolic syndrome compared to children and adolescents without OSAHS. The presence of obesity and daytime hypoventilation $\left(\mathrm{PaCO}_{2}{ }^{3} 45 \mathrm{mmHg}\right.$ ) configure another syndrome defined as Obesity Hypoventilation Syndrome (OHS). In more than $90 \%$ of cases OHS is linked with OSAHS; however, the presence of OSAHS is not necessary for diagnosis of OHS ${ }^{24}$.

Obesity may alter the normal mechanics of the upper airways and thus contribute to the pathophysiology of OSAHS mainly in two ways: through the lipid backlog in peripharyngeal tissues and the increased respiratory effort related to abdominal weight ${ }^{13}$. In addition, a role in the relationship between obesity and OSAHS is also played by leptin and other factors, such as hypoxia, increased sympathetic tonus, oxidative stress, inflammation and endothelial dysfunction ${ }^{25}$.

\section{Lipid backlog in pharyngeal structures}

Upper airway structural alterations in obesity are in first place related to adipose deposition in peripharyngeal tissues and in pharyngeal lumen, lateral wall and muscles: this consequently leads to collapse of lateral, rather than anterior, pharyngeal structures and to a greater susceptibility to OSAHS ${ }^{26}$. 
The fatty deposits responsible of this enhanced collapsibility are particularly pronounced in men with central obesity compared to women with peripheral adiposity. During sleep, when neuromuscular activity is reduced, central obesity then can obliterate the pharyngeal lumen, increasing surrounding tissue pressures and leading to elevations in pharyngeal collapsibility ${ }^{11}$ : these patients will have a very low sleep quality, as well as a high risk of cardiovascular disease ${ }^{27}$.

In addition, patients with OSAHS show an oval shape of pharyngeal lumen and this shape further reduces the ability of muscles to dilate the pharynx ${ }^{28}$.

\section{Reduction of lung volumes}

Obesity, and especially central obesity, also acts on lung volumes, causing their reduction. Indeed, fat accumulating in the thorax and abdomen prevents regular lung expansion: this provokes a fall of functional residual capacity (FRC) ${ }^{11}$, with a subsequent loss of caudal traction on upper airway structures ${ }^{29}$. As caudal traction decreases, pharyngeal and global airway collapsibility substantially grow ${ }^{30}$, leading to a reduction in axial tension within the pharyngeal wall ${ }^{31}$, but also to a decrease in ventilation of the lung bases, to ventilation-perfusion mismatch and to enlargement of the alveolar-arterial $\mathrm{PO}_{2}$ difference ${ }^{32}$. Low FRC also predisposes to instability of the respiratory control system. In the long run, the presence of recurrent airway obstruction, intermittent hypoxia and associated arousals causes oscillation of systemic and pulmonary arterial blood pressures, triggering or exacerbating heart disease ${ }^{33}$.

\section{The role of leptin}

Metabolic and humoral factors that determine the distribution of adiposity may be responsible for OSAHS. Among these there is leptin, a satiety hormone produced by adipocytes that, in physiological conditions, is released into the circulation in proportion to body adiposity ${ }^{34}$ : in fact, it is produced in abundance by subcutaneous adipose tissue, particularly in women, and limits central obesity. From adipose tissue, leptin circulates to the brain, where it interacts with receptors in the hypothalamus to suppress appetite and regulate body composition and adiposity distribution ${ }^{35}$.

Obese subjects have elevated levels of circulating leptin, on one hand essentially because of the increase of adipocytes and fat mass, but on the other for central resistance to leptin ${ }^{12,36}$ : consequently, in obesity the central satiety effects of leptin is abrogated ${ }^{12}$.

Leptin resistance is defined as a failure of high-circulating levels of leptin to decrease hunger and promote energy ex- penditure ${ }^{37}$. At least three possible mechanisms have been proposed to mediate leptin resistance, including a failure of circulating leptin to reach its targets in the brain because of limited permeability of the blood-brain barrier; a downregulation of the leptin receptors on the cell surface; and/ or an inhibition of the leptin-receptor signalling pathway ${ }^{38}$. Besides the action on satiety, leptin is also a potent ventilation stimulant acting on central respiratory control nuclei ${ }^{12}$ : from this point of view, leptin resistance is implicated in the pathogenesis of OSAHS through impaired central regulation of upper airway patency and diaphragmatic control ${ }^{39}$. Furthermore, high levels of plasma leptin are also related to obesity hypoventilation ${ }^{40}$.

However, hyperleptinaemia is associated with OSAHS itself ${ }^{41}$, with a positive correlation between plasma leptin levels and severity of disease and independence from BMI or waist circumference ${ }^{42}$.

\section{Inflammation}

Adipose tissue is an abundant source of pro-inflammatory cytokines, including tumour necrosis factor (TNF- $\alpha$ ) and interleukin-6 (IL-6) ${ }^{43}$. These cytokines may be responsible of defects in neuromuscular control of the upper airway leading to OSAHS seen especially in patients with visceral obesity ${ }^{44}$. TNF- $\alpha$, in particular, exerts somnogenic effects on the central nervous system ${ }^{45}$ stimulating membrane expression and release of its soluble receptor TNF- $\alpha$ receptor I (TNF $\alpha$ RI). The levels of TNF $\alpha$ RI in plasma fall with the use of CPAP ${ }^{46}$, which corroborates the potential role of inflammation in the natural history of OSAHS.

\section{OSAHS and obesity: a biunivocal relationship}

Although obesity is the main risk factor for the development of OSAHS, some authors have suggested that OSAHS can cause weight gain and therefore obesity ${ }^{46}$ : in fact, it seems that these two conditions form a vicious cycle where each results in the worsening of the other ${ }^{47}$ and whose main actors include reduced physical activity, insulin resistance and increased leptin and ghrelin levels ${ }^{22}$ (Fig. 1).

One of the most prominent symptoms of OSAHS is excessive daytime somnolence ${ }^{1}$, which may result in decreased physical activity, in turn responsible for weight gain if not associated with reduced caloric intake ${ }^{48}$ : patients with OSAHS are at high risk of obesity, with consequent worsening of their apnoeas ${ }^{48}$. This relationship is also confirmed by the fact that OSAHS treatment improve alertness and daytime activity, while untreated patients tend to gain weight ${ }^{49,50}$.

The appearance of obesity in patients affected by OSAHS 


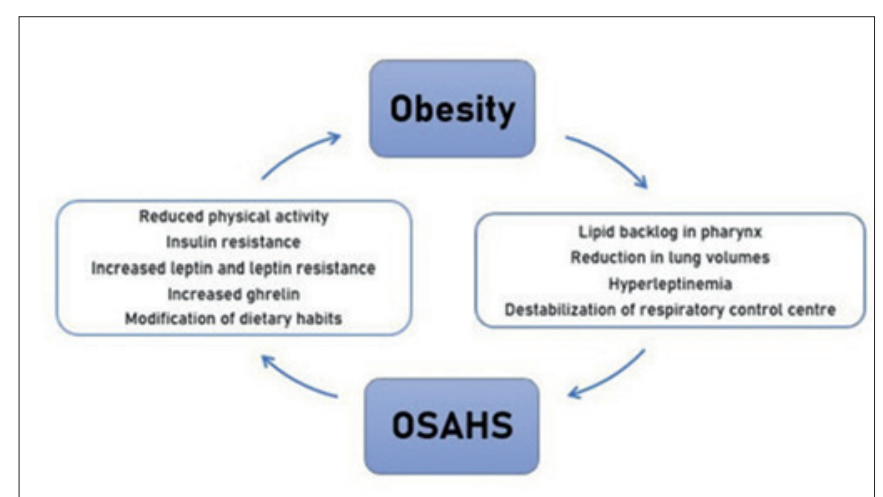

Figure 1. Possible mechanisms at the base of relationship between OSAHS and obesity.

is also potentially influenced by a change in dietary habits in favour of high caloric items, such as refined carbohydrates, which leads to positive energy balance seen in this population ${ }^{38}$, maybe as a form of stress response ${ }^{51}$.

OSAHS may predispose individuals to obesity also because of disrupted metabolism. In fact, sleep fragmentation and deprivation are associated with increased glucose tolerance and insulin resistance, with consequent increased risk for obesity and diabetes ${ }^{52}$. The exact mechanism leading to insulin resistance in patients with OSAHS is not fully understood: a proposed hypothesis is that sleep deprivation itself determines peripheral decreased insulin sensitivity, with a long-term progressive exhaustion of its reserves in pancreatic islands; on the other hand, another potential mechanism of insulin resistance may involve the elevated sympathetic activity in OSAHS ${ }^{53}$. However, it has been observed that insulin sensitivity improves after almost three months of treatment with continuous positive airway pressure (CPAP), one of cornerstones of OSAHS therapy ${ }^{54}$.

It has been suggested that hyperleptinaemia may be a prognostic marker for OSAHS ${ }^{42}$; at same time, several studies have confirmed that OSAHS may directly influence leptin metabolism. Because in patients with OSAHS leptin levels are high independently of body fat content, it was postulated that OSAHS is associated with resistance to the weightreducing effects of leptin ${ }^{41}$, with increased appetite and body weight. These effects cease when treatment with nasal CPAP is initiated ${ }^{55,56}$ and reduction in circulating leptin levels was not restricted to the CPAP therapy only, but also reported after surgical intervention with uvulopalatopharyngoplasty ${ }^{57}$.

Another relatively recent discovered hormone that regulates appetite and body weight is ghrelin, a hormone which stimulates appetite and whose levels are increased in OSAHS patients ${ }^{58}$ : therefore, in these patients it contributes to higher caloric intake and obesity.

\section{Diagnosis of OSAHS}

The first step to diagnose OSAHS and understand its severity is to obtain the apnoea-hypopnoea index (AHI), which is the mean number of sleep apnoeas and hypopneas per hour. Based on the AHI, OSAHS is then defined as 5 or more episodes of apnoea or hypopnoea per hour of sleep with associated symptoms (e.g., excessive daytime sleepiness, fatigue, impaired cognition) or 15 or more obstructive apnoea-hypopnea events per hour of sleep without symptoms ${ }^{59,60}$ : in this way, OSAHS is classified as "mild" between 5 and 14 events, "moderate" between 15 and 29 and "severe" when more than 30 episodes occur per hour of sleep ${ }^{59}$. It should be emphasised that the diagnosis of OSAHS does not change between obese and non-obese patients. Obesity is only a causal factor for the syndrome that can worsen the pathological picture. It is implicated that it has shown bidirectional causality with each other, and that it may have mutual interaction with the other metabolic dysregulations.

However, medical history and physical examination are the cornerstones of clinical diagnosis. Patients should be interrogated about their nocturnal and daytime symptoms, extending questions to bedpartner to know other important information about the patient's sleep. Furthermore, given the close association between OSAHS and cardiovascular disease, OSAHS should be suspected in individuals affected by systemic or pulmonary hypertension, metabolic syndrome, heart failure, or arrhythmias ${ }^{1}$.

Physical examination of affected patients should include respiratory, cardiovascular and neurologic systems ${ }^{60}$ and, especially in case of obese patients, should be comprehensive of determination of some anthropometric parameters, which, if increased, raise the probability of OSAHS and pharyngeal obstruction. The most important of these parameters is body mass index (BMI), which becomes an alarm value if over 29.9. The measurement of neck circumference allows estimating the risk of suffering from OSAHS: this risk is clearly increased if the neck circumference is greater than $41 \mathrm{~cm}$ in women and $43 \mathrm{~cm}$ in men ${ }^{61}$. Furthermore, with a simple inspection of the oral cavity, it is possible to evaluate the Mallampati score and to quantify the degree of tonsillar hypertrophy ${ }^{62}$ : in general, if the Mallampati score is low, the degree of tonsillar hypertrophy will be greater, with a consequently higher risk of OSAHS. After clinical evaluation of the patient, it is necessary to confirm the suspicion of OSAHS, in order to assess its severity and guide therapeutic choices: the gold standard is polysomnography, rather than night cardiorespiratory monitoring and endoscopy, including sleep endoscopy. 


\section{Objective sleep studies}

\section{First step: polysomnography}

One method used to screen obstructive sleep apnoea is the continuous recording of oxygen saturation during sleep. This method is economic and easily practicable; however, it is often not sufficiently sensible or specific and its utility in clinical practice is poor ${ }^{63}$.

On the contrary, polysomnography is the gold standard for the diagnosis of OSAHS, because it consents to identify affected patients and to stratify disease severity, in addition to recognition of co-existing sleep disorders, including other forms of sleep-disordered breathing. Usually performed in a laboratory during the sleep of patient, the exam allows measurement and recording of several physiological variables, including pulse oximetry, electroencephalogram, electro-oculogram, nasal and oral airflow measurements, chest wall movements, electromyogram and electrocardiogram. An obstructive apnoea is defined as a cessation of airflow for at least $10 \mathrm{sec}$ despite ongoing inspiratory effort; instead, hypopnea is defined by one of the following three features: more than $50 \%$ airflow reduction, moderate airflow reduction $(50 \%)$ associated with oxyhaemoglobin desaturation and moderate airflow reduction with electroencephalographic evidence of awakening ${ }^{57}$.

\section{Endoscopy}

In patients with OSAHS, pharyngeal obstruction may be located at multiple levels (soft palate, lateral pharyngeal wall, tonsils, tongue base, epiglottis) and its identification is important for proper treatment. To date, to identify the site of upper airway obstruction nasopharyngolaryngoscopy is mandatory, because this exam allows for complete visualisation of the pharynx ${ }^{13}$. Currently, there are two methods for performing endoscopy in OSAHS patients: during wakefulness with Müller's manoeuvre and during drug-induced sleep (the so-called sleep endoscopy).

Nasopharyngoscopy with Müller's manoeuvre (maximum inspiration with both the mouth and the nose occluded, in way to simulate apnoea) is routinely used to identify the sites responsible for increase in airflow resistance: in physiological conditions, after manoeuvre, the airway lumen remains patent (Müller -), while in OSAHS patients it narrows (Müller + ). However, the use of endoscopy with Müller's manoeuvre is controversial and shows some limitations: in the first instance, is not an objective test because the degree of pharyngeal collapse closely depends on inspiratory effort during the manoeuvre; furthermore, it investigates the dynamic behaviour of the upper airway during wakefulness, whereas hypotonia and pharyngeal collapse typically occur during sleep ${ }^{64,65}$.
Given the limits of classic waking endoscopy, nowadays the gold standard for the diagnosis of obstructive sites in patients with OSAHS is drug-induced sleep/sedation endoscopy (DISE), i.e. endoscopy performed during induced sleep ${ }^{66}$ in an operating room ${ }^{67}$. It is a relatively quick and simple technique that can be performed on an outpatient basis, targeting possible vibration and obstruction sites ${ }^{68}$, in addition to degree and pattern of collapse ${ }^{13}$. Several anaesthetic drugs may be used to induce sleep, alone or in association, among which the most used is propofol. DISE can be used in all patients with snoring or OSAHS; nevertheless, it is contraindicated in patients with severe respiratory pathology, while coronary or heart failure are relative contraindications to propofol ${ }^{69}$.

The obstruction implicated in abnormal respiratory events are clumsily attributable to four regions: retrovelar area, oropharynx, hypopharynx and larynx, each of which presents various structures that can induce obstruction ${ }^{70}$. Several systems are used to describe and classify obstructing and vibrating structures noticed with DISE: one is NOHL classification ${ }^{71}$, which also includes nasal obstruction $(\mathrm{N})$ that may equally well be assessed during wakefulness, in addition to the oropharynx (Fig. 2) and retropalatal area (O) (Fig. 3), hypopharynx and retrolingual area (H) (Fig. 4) and larynx (L) (Figs. 5, 6). For each district, NOHL classification evaluates collapse/vibration degree (from 0 if absent, to 4 if superior to $75 \%$ ) and obstruction pattern (anteroposterior, transverse or circumferential). In addition, including nasal cavity, this classification introduces a therapeutic aspect unlike other classifications based on anatomic description alone: in fact, to understand the correct obstructive site and the type of obstructive pattern is mandatory for the choice of the proper surgical technique ${ }^{13}$.

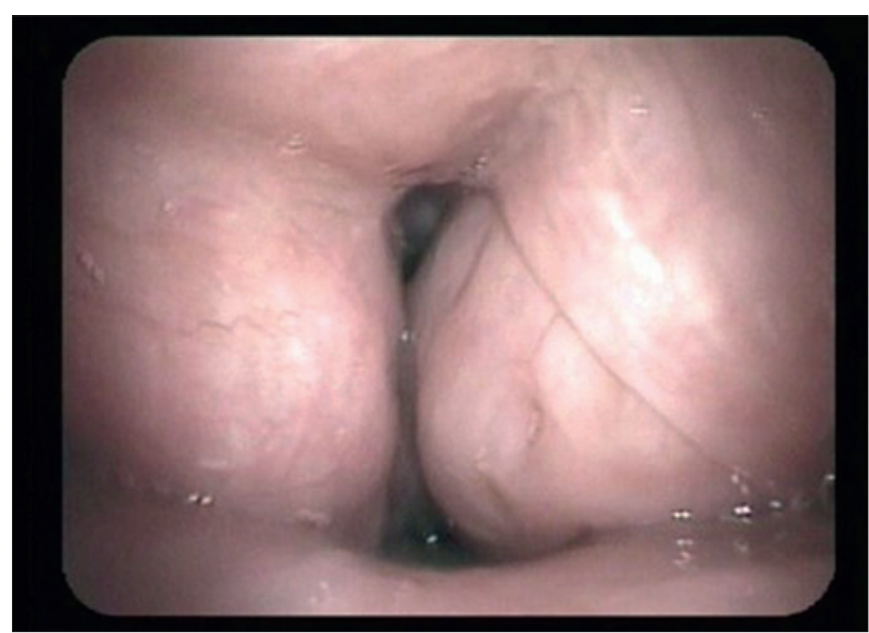

Figure 2. Sleep endoscopy showing oropharynx obstruction. 


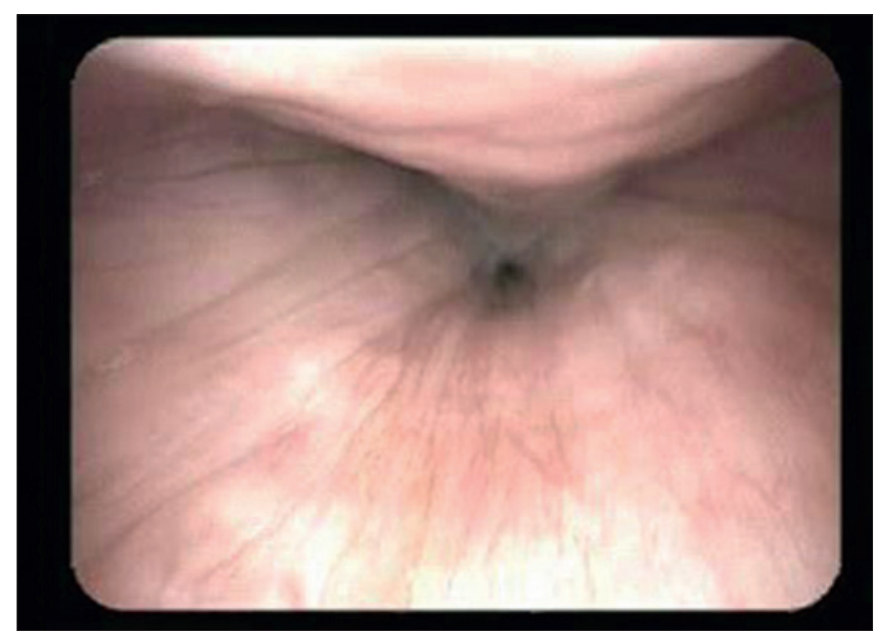

Figure 3. Sleep endoscopy showing retropalatal area obstruction.

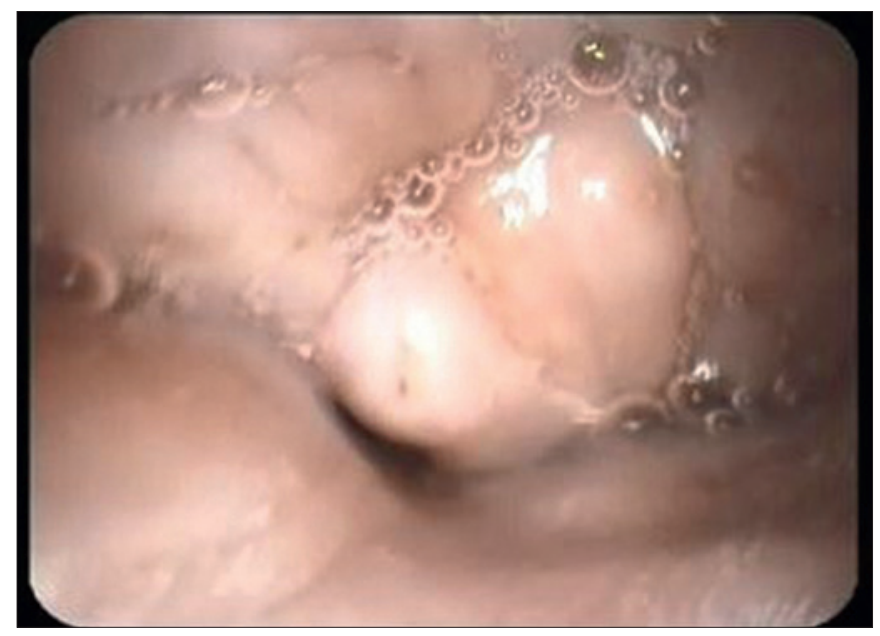

Figure 4. Sleep endoscopy showing hypopharynx obstruction.

\section{Therapeutic options for obese patients with OSAHS}

The variety of symptoms and signs of OSAHS has made this disease the subject of study for many specialists including neurologists, pneumologists and otolaryngologists who have introduced the main surgical therapeutic options. Recently, the dentist and maxillofacial surgeon have been introduced in management of OSAHS and their contribution seems to play an increasingly important role. However, since this pathology involves many organs and systems, it is clear that many specialists are involved in it. All these specialists, including cardiologists, must be involved in a diagnostic and therapeutic path and a multidisciplinary strategy with the aim of obtaining satisfactory therapeutic results in the treatment of patients with

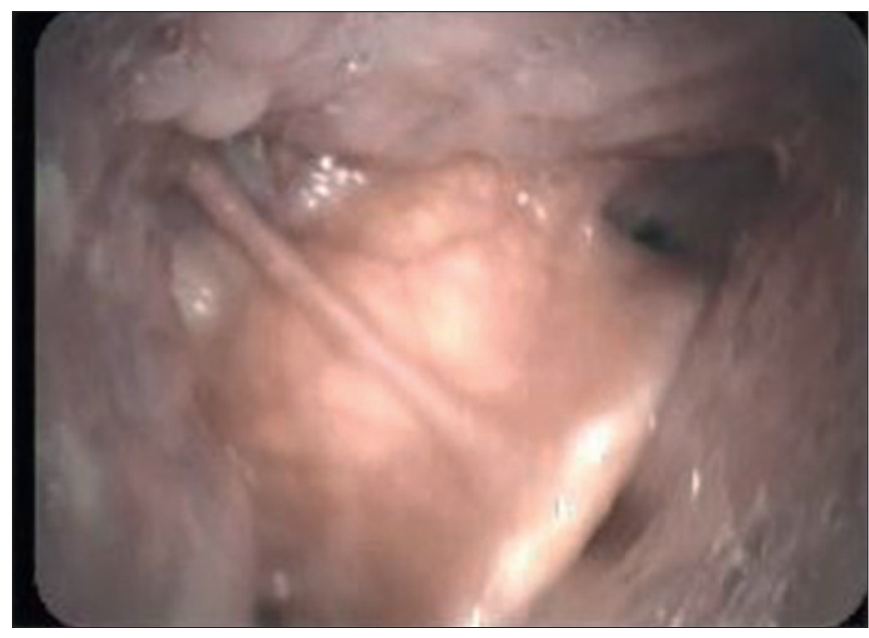

Figure 5. Sleep endoscopy showing larynx collapse (type closing door).

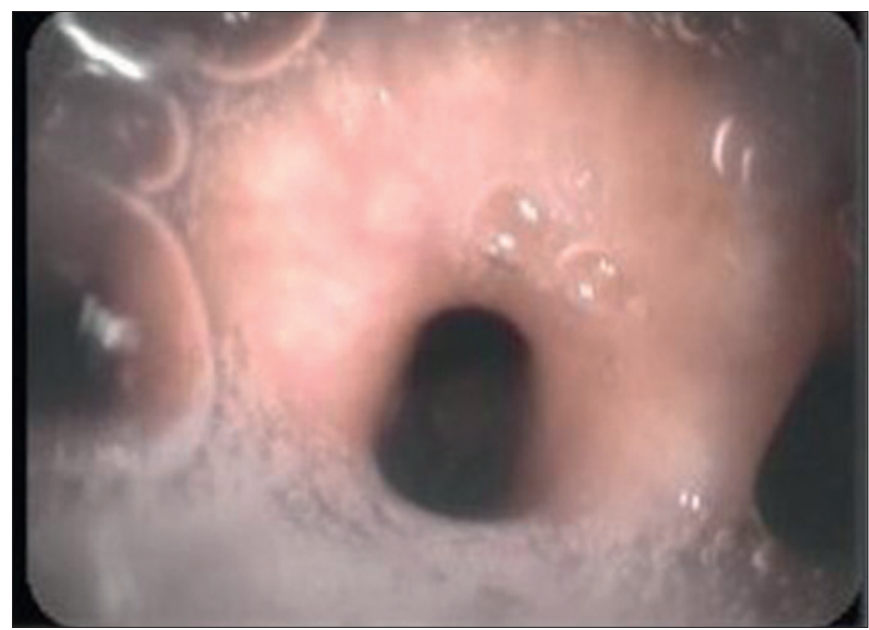

Figure 6. Sleep endoscopy showing larynx collapse (type closing book).

OSAHS ${ }^{72,73}$. The ideal strategy is to tailoring surgery on every single case.

\section{Behavioural options: lifestyle changes and weight loss}

In the first instance, OSAHS therapy is behavioural, based on lifestyle changes and weight loss, that to date are cornerstones of treatment ${ }^{25}$. The most effective behavioural measure is weight loss ${ }^{1}$, which helps to reduce OSAHS severity up to arrive sometimes to its resolution ${ }^{74}$ : in patients with mild disease, a weight loss of $10.7 \mathrm{~kg}$ is associated by $40 \%$ reduction in AHI, while in obese patients with moderate to severe sleep apnoea the reduction of $\mathrm{AHI}$ is of $67 \%$ and in patients with severe OSAHS benefit even more ${ }^{75}$. 
Weight loss also allows to attenuate cardiometabolic abnormalities associated to OSAHS, with beneficial changes in cholesterol, insulin resistance, leptin, inflammatory markers and endothelial function ${ }^{76,77}$.

The first way to achieve weight loss is through conservative strategies, such as diet, exercise and medications: in particular, in sedentary overweight/obese adults, exercise may be beneficial for treatment of OSAHS not only because it facilitates weight loss ${ }^{78}$, but also because it seems to rise respiratory drive and to stabilise muscle tone in the upper airway ${ }^{79}$. Exercise and the Mediterranean diet, however, have positive effects on the severity of OSAHS even independently of weight loss.

Nevertheless, in many cases weight loss is hard to achieve and maintain using conservative strategies, and bariatric surgery has emerged as an alternative treatment of severe or complicated obesity, which offers a dramatic weight reduction, often maintained for up to 10 years ${ }^{80}$, but also important results in reference to sleep apnoea severity and cardiometabolic disturbances. Obese patients undergoing bariatric surgery have shown a prevalence of OSAHS more than $70 \%$ and it has been demonstrated that at one year later gastric banding surgery they present significant increases in rapid eye movement and slow-wave sleep, with reduced daytime sleepiness. Overall, patients undergoing bariatric surgery (regardless of the type of intervention) show an average reduction of $15 \mathrm{~kg} / \mathrm{m}^{2}$ in BMI and 36 events/hour in the AHI, suggesting that every 1 unit reduction in BMI translates to a reduction of 2.3 units in the AHI. However, OSAHS resolves completely only in $4 \%$ of subjects treated with bariatric surgery, perhaps because most of these patients, despite significant reduction in weight, remain overweight.

\section{Continuous positive airway pressure (CPAP)}

Continuous positive airway pressure (CPAP) is now considered the treatment of choice for OSAHS, especially in severe forms, by virtue of its remarkable effectiveness in reducing symptoms and the possible sequelae of the disease ${ }^{81-84}$. It consists in continuous insufflation of air under pressure through nose during sleep, which prevent partial or complete collapse of the upper airway ${ }^{1}$.

Polysomnographic studies have demonstrated that treatment with CPAP is able to restore patency of the airway and to reverse apnoea and hypopnoea, with regression of symptoms, improvement of daytime sleepiness and neurocognitive performance, and clear reduction of $\mathrm{AHI}{ }^{85}$. In addition, nasal CPAP may lead to reduced incidence of cardiovascular events, to improvement of blood pressure and metabolic abnormalities ${ }^{1}$ and to better glycaemic control and insulin sensitivity in patients with concomitant type 2 diabetes. In obese patients, CPAP treatment of OSAHS is also able to determine weight loss and decrease of intraabdominal fat, probably because of decreased daytime hypersomnolence and increased physical activity ${ }^{1}$. Reduction of visceral fat is also seen in patients without significant weight loss.

Despite all these benefits, noncompliance is evident in a significant proportion of patients ${ }^{86}$, for which CPAP is poorly tolerated because of size and noise of the equipment, but also for adverse effects, which include irritation, pain, rash and skin breakdown at mask contact points, dryness or irritation of the nasal and pharyngeal membranes, nasal congestion, rhinorrhoea and eye irritation ${ }^{1}$. Furthermore, the benefits of CPAP therapy on metabolic parameters in subjects with mild and moderate OSAHS also remain unclear. Up to now, no studies have determined whether the efficacy of CPAP is still adequate at more than 3 months after the start of the treatment ${ }^{87}$.

\section{Mandibular advancement devices (MAD)}

In case of failure or in patients who refuse CPAP, a therapeutic alternative is represented by mandibular advancement devices (MAD), which maintain the patency of the airways posterior to the tongue advancing and/or closing the jaw during the sleep ${ }^{87}$, promoting advancement of the tongue, increased tension of the pharyngeal walls, impossibility of the jaw to post-rotate and, consequently, prevent airway obstruction ${ }^{88}$.

Ideally, the patient should be treated by the dentist with individualised and adjustable devices for his/her case, whereby the application is preceded by dental arch impressions or scans. Once applied, the device should allow progressive adjustment of the mandibular protrusion ${ }^{89}$, ensuring the maximum comfort, without algic symptoms affecting the muscle component or the temporomandibular joint (TMJ). However, it is important to start using the device gradually, increasing the time of use day by day. At the end of the gradual MAD adjustment period, which can take from 3 to 5 months, a new polysomnography should be performed to quantify the obtained gains ${ }^{20}$.

Although less effective than CPAP, MAD have given positive results in the treatment of OSAHS ${ }^{90}$, although limited to the moment in which patient is using the device ${ }^{20}$, which are preferentially indicated for mild or moderate OSAHS ${ }^{91}$. Compared to CPAP, these devices have the advantage of being unobtrusive, make no noise and are potentially less expensive, and are generally preferred by patients. Prescinotto et al. reported a success rate of $64.3 \%$ using MAD ${ }^{92}$. Nevertheless, they may be associated with some adverse 
effects: among these, one that occurs in practically every individual who wears a MAD for a prolonged period of time is tooth movement ${ }^{93}$.

\section{Surgery}

Some OSAHS cases require surgical modifications of the anatomy of the upper airway. In this case, appropriate patient selection and surgeon experience are crucial for therapeutic success ${ }^{1}$.

Surgical options include several procedures, with different degrees of invasiveness, with the aim to remove respiratory obstructive factors in the anatomical districts of ENT interest $^{1}$ : in over $75 \%$ of cases, however, these interventions are directed to the nose, palate and lateral walls of the pharynx and, among them, the most popular procedures are uvulopalatopharyngoplasty (UPPP) and lateral pharyngoplasty techniques ${ }^{94}$. On the other hand, soft tissue modifications can also be obtained by maxillofacial skeletal surgery, and more specifically maxillomandibular orthognathic surgery ${ }^{20}$.

Uvulopalatopharyngoplasty involves resection of the tonsils (if present), uvula, and posterior palate and reorientation of the tonsillar pillars, eventually with the help of harmonic scalpel ${ }^{95}$ or other devices to remove redundant mucosa and to create a neouvula. Another variant is laserassisted uvulopalatoplasty (LAUP), an outpatient surgical technique that involves a series of laser incisions and vaporisations designed to shorten the uvula and modify and tighten the soft palatal tissue ${ }^{1}$. Millman et al. ${ }^{96}$ reported a UPPP success rate ranging from $27 \%$ to $50 \%$. UPPP has shown a significant reduction in AHI, unlike LAUP, which results in modest AHI reduction and little or no reduction in daytime symptoms.

Of the different lateral pharyngoplasty techniques used, barbed reposition pharyngoplasty (BRP) has recently become one of the most practiced palatal surgery techniques in different countries ${ }^{97}$ : performed with barbed suture, i.e. knotless bidirectional resorbable suture, it allows obtaining suspension of the palatopharyngeal muscle to stable structures such as the pterygomandibular raphe, with consequent expansion of the lateral walls of the oropharynx without tissue resection of the soft palate region. The success rate reported for patients underwent BRP is $86 \%$ with a cure rate of $18 \%{ }^{98}$. This technique is simple, quick, easy to learn and safe ${ }^{98,99}$, with promising results in the management of OSAHS in single and multilevel surgery and an important reduction of post-operative AHI.

Maxillo-mandibular advancement osteotomy (MMA) aims to enlarge the velo-orohypopharyngeal airway by advancing the anterior pharyngeal tissues (soft palate, tongue base and suprahyoid musculature) attached to the maxilla, mandible and hyoid bone ${ }^{1}$. Adjunctive procedures, such as cervical lipectomy, adenotonsillectomy and others, may also be done during the same surgical procedure ${ }^{100}$. The rate of success is $60 \%$ on a long-term basis using this surgical procedure ${ }^{100}$. MMA is particularly appropriate for patients with skeletal hypoplasia, retrognathia and severe OSAHS, since it ensures substantial and consistent reduction in AHI, greater than those obtained with UPPP, with few adverse events; nevertheless, it is relatively expensive ${ }^{20}$.

However, in the context of OSAHS surgery, other procedures are also included, such as radiofrequency ablation, whose purpose is to modify the anatomic site of the obstruction acting on nasal turbinates, tongue base and palate, with minimal invasiveness and very few risks. These procedures may be considered for patients whose main complaint is snoring, with little or no apnoea.

\section{References}

1 Mannarino MR, Di Filippo F, Pirro M. Obstructive sleep apnea syndrome. Eur J Intern Med 2012;23:586-593. https://doi.org/10.1016/j. ejim.2012.05.013

2 Huon LA, Guilleminault C. A succinct history of sleep medicine. Adv Otorhinolaryngol 2017;80:1-6. https://doi.org/10.1159/000470486

3 Senaratna CV, Perret JL, Lodge CJ, et al. Prevalence of obstructive sleep apnea in the general population: a systematic review. Sleep Med Rev 2017;34:70-81. https://doi.org/10.1016/j.smrv.2016.07.002

4 Peppard PE, Young T, Barnet JH, et al. Increased prevalence of sleepdisordered breathing in adults. Am J Epidemiol 2013;177:1006-1014. https://doi.org/10.1093/aje/kws342

5 Young T, Peppard PE, Gottlieb DJ. Epidemiology of obstructive sleep apnea: a population health perspective. Am J Respir Crit Care Med 2002;165:1217-1239. https://doi.org/10.1164/rccm.2109080

6 Krakow B, Melendrez D, Ferreira E, et al. Prevalence of insomnia symptoms in patients with sleep disordered breathing. Chest 2001;120:1923-1929. https://doi.org/10.1378/chest.120.6.1923

7 Oztura I, Kaynak D, Kaynak HC. Nocturia in sleep-disordered breathing. Sleep Med 2006;7:362-367. https://doi.org/10.1016/j. sleep.2005.10.004

8 Horstmann S, Hess CW, Bassetti C, et al. Sleepiness-related accidents in sleep apnea patients. Sleep 2000;23:383-389.

9 Knauert M, Naik S, Gillespie MB, et al. Clinical consequences and economic costs of untreated obstructive sleep apnea syndrome. World J Otorhinolaryngol Head Neck Surg 2015;1:17-27. https://doi. org/10.1016/j.wjorl.2015.08.001

10 Aloia MS, Arnedt JT, Davis JD, et al. Neuropsychological sequelae of obstructive sleep apnea-hypopnea syndrome: a critical review. J Int Neuropsychol Soc 2004;10:772-785. https://doi.org/10.1017/ S1355617704105134

11 Schwartz AR, Patil SP, Squier S, et al. Obesity and upper airway control during sleep. J Appl Physiol 2010;108:430-435. https://doi. org/10.1152/japplphysiol.00919.2009

12 Berger S, Polotsky VY. Leptin and leptin resistance in the pathogenesis of obstructive sleep apnea: a possible link to oxidative stress and cardiovascular complications. Oxid Med Cell Longev 2018;2018:5137947. https://doi.org/10.1155/2018/5137947 
13 Cavaliere M, Russo F, Iemma M. Awake versus drug-induced sleep endoscopy: evaluation of airway obstruction in obstructive sleep apnea/hypopnoea syndrome. Laryngoscope 2013;123:2315-2318. https://doi.org/10.1002/lary.23881

14 Badr MS. Pathophysiology of upper airway obstruction during sleep. Clin Chest Med 1998;19:21-32. https://doi.org/10.1016/ s0272-5231(05)70429-9

15 Gozal D. Sleep-disordered breathing and school performance in children. Pediatrics 1998;102:616-620. https://doi.org/10.1542/ peds.102.3.616

16 Iida-Kondo C, Yoshino N, Kurabayashi T, et al. Comparison of tongue volume/oral cavity volume ratio between obstructive sleep apnea syndrome patients and normal adults using magnetic resonance imaging. J Med Dent Sci 2006;53:119-126.

17 Narang I, Al-Saleh S, Amin R, et al. Utility of neck, height, and tonsillar size to screen for obstructive sleep apnea among obese youth. Otolaryngol Head Neck Surg 2018;158:745-751. https://doi. org/10.1177/0194599817740349

18 Faber J, Faber C, Faber AP. Obstructive sleep apnea in adults. Dental Press J Orthod 2019;24:99-109. https://doi.org/10.1590/21776709.24.3.099-109.sar

19 Kolla BP, Foroughi M, Saeidifard F, et al. The impact of alcohol on breathing parameters during sleep: a systematic review and metaanalysis. Sleep Med Rev 2018;42:59-67. https://doi.org/10.1016/j. smrv.2018.05.007

20 Madkikar N, Pandey S, Ghaisas V. Multi level single stage: barbed reposition pharyngoplasty and nasal surgery in treatment of osa - our experience. Indian J Otolaryngol Head Neck Surg 2019;71:309-314. https://doi.org/10.1007/s12070-019-01694-y

${ }^{21}$ Redline S, Kump K, Tishler PV, et al. Gender differences in sleep disordered breathing in a community-based sample. Am J Respir Crit Care Med 1994;149:722-726. https://doi.org/10.1164/ ajrccm.149.3.8118642

22 Rudnick EF, Walsh JS, Hampton MC, et al. Prevalence and ethnicity of sleep-disordered breathing and obesity in children. Otolaryngol Head Neck Surg 2007;137:878-882. https://doi.org/10.1016/j. otohns.2007.08.002

23 Morrison JA, Friedman LA, Gray-McGuire C. Metabolic syndrome in childhood predicts adult cardiovascular disease 25 years later: the Princeton Lipid Research Clinics Follow-up Study. Pediatrics 2007;120:340-345. https://doi.org/10.1542/peds.2006-1699

24 Athayde RAB, Oliveira Filho JRB, Lorenzi Filho G, et al. Obesity hypoventilation syndrome: a current review. J Bras Pneumol 2018;44:510518. https://doi.org/10.1590/S1806-37562017000000332

25 Kuvat N, Tanriverdi H, Armutcu F. The relationship between obstructive sleep apnea syndrome and obesity: a new perspective on the pathogenesis in terms of organ crosstalk. Clin Respir J 2020;14:595604. https://doi.org/10.1111/crj.13175

26 Schwab RJ, Gupta KB, Gefter WB, et al. Upper airway and soft tissue anatomy in normal subjects and patients with sleep-disordered breathing. Significance of the lateral pharyngeal walls. Am J Respir Crit Care Med 1995;152:1673-1689. https://doi.org/10.1164/ ajrccm.152.5.7582313

27 Schafer H, Pauleit D, Sudhop T, et al. Body fat distribution, serum leptin, and cardiovascular risk factors in men with obstructive sleep apnea. Chest 2002;122:829-839. https://doi.org/10.1378/ chest.122.3.829

28 Leiter JC. Upper airway shape: is it important in the pathogenesis of obstructive sleep apnea? Am J Respir Crit Care Med 1996;153:894898. https://doi.org/10.1164/ajrccm.153.3.8630569
29 Van de Graaff WB. Thoracic traction on the trachea: mechanisms and magnitude. J Appl Physiol 1991;70:1328-1336. https://doi. org/10.1152/jappl.1991.70.3.1328

30 Tagaito Y, Isono S, Remmers JE, et al. Lung volume and collapsibility of the passive pharynx in patients with sleep-disordered breathing. J Appl Physiol 2007;103:1379-1385. https://doi.org/10.1152/ japplphysiol.00026.2007

31 Rowley JA, Permutt S, Willey S, et al. Effect of tracheal and tongue displacement on upper airway airflow dynamics. J Appl Physiol 1996;80:2171-2178. https://doi.org/10.1152/jappl.1996.80.6.2171

32 Gifford AH, Leiter JC, Manning HL. Respiratory function in an obese patient with sleep-disordered breathing. Chest 2010;138:704-715. https://doi.org/10.1378/chest.09-3030

33 Oldenburg O, Lamp B, Topfer V, et al. Prevalence of sleep-related breathing disorders in ischemic and non-ischemic heart failure. Dtsch Med Wochenschr 2007;132:661-666. https://doi. org/10.1055/s-2007-973599

34 Considine RV, Sinha MK, Heiman ML, et al. Serum immunoreactive-leptin concentrations in normal-weight and obese humans. N Engl J Med 1996;334:292-295. https://doi.org/10.1056/ NEJM199602013340503

35 Breslow MJ, Min-Lee K, Brown DR, et al. Effect of leptin deficiency on metabolic rate in ob/ob mice. Am J Physiol Endocrinol Metab 1999;276:443-449. https://doi.org/10.1152/ajpendo.1999.276.3.E443

36 Enriori PJ, Evans AE, Sinnayah P, et al. Leptin resistance and obesity. Obesity (Silver Spring) 2006;14:254-258. https://doi.org/10.1038/ oby.2006.319

37 Flier JS. Hormone resistance in diabetes and obesity: insulin, leptin, and FGF21. Yale J Biol Med 2012;85:405-414.

38 Ong CW, O'Driscoll DM, Truby H, et al. The reciprocal interaction between obesity and obstructive sleep apnoea. Sleep Med Rev 2013;17:123-131. https://doi.org/10.1016/j.smrv.2012.05.002

39 Imayama I, Prasad B. Role of leptin in obstructive sleep apnea. Ann Am Thorac Soc 2017;14:1607-1621. https://doi.org/10.1513/ AnnalsATS.201702-181FR

40 Phipps PR, Starritt E, Caterson I, et al. Association of serum leptin with hypoventilation in human obesity. Thorax 2002;57:75-76. https://doi.org/10.1136/thorax.57.1.75

41 Phillips BG, Kato M, Narkiewicz K, et al. Increases in leptin levels, sympathetic drive, and weight gain in obstructive sleep apnea. Am J Physiol Heart Circ Physiol 2000;279:234-237. https://doi. org/10.1152/ajpheart.2000.279.1.H234

42 Öztürk L, Ünal M, Tamer L, et al. The association of the severity of obstructive sleep apnea with plasma leptin levels. Arch Otolaryngol Head Neck Surg 2003;129:538-540. https://doi.org/10.1001/ archotol.129.5.538

43 Fried SK, Bunkin DA, Greenberg AS. Omental and subcutaneous adipose tissues of obese subjects release interleukin-6: depot difference and regulation by glucocorticoid. J Clin Endocrinol Metab 1998;83:847-850. https://doi.org/10.1210/jcem.83.3.4660

44 Vgontzas AN, Zoumakis E, Lin HM, et al. Marked decrease in sleepiness in patients with sleep apnea by etanercept, a tumor necrosis factor-alpha antagonist. J Clin Endocrinol Metab 2004;89:4409-4413. https://doi.org/10.1210/jc.2003-031929

45 Churchill L, Rector DM, Yasuda K, et al. Tumor necrosis factor alpha: activity dependent expression and promotion of cortical column sleep in rats. Neuroscience 2008;156:71-80. https://doi.org/10.1016/j. neuroscience.2008.06.066

46 Arias MA, Garcia-Rio F, Alonso-Fernandez A, et al. CPAP decreases plasma levels of soluble tumour necrosis factor-alpha receptor 1 in obstructive sleep apnoea. Eur Respir J 2008;32:1009-1015. https:// doi.org/10.1183/09031936.00007008 
47 Unnikrishnan D, Jun J, Polotsky V. Inflammation in sleep apnea: an update. Rev Endocr Metab Disord 2015;16:25-34. https://doi. org/10.1007/s11154-014-9304-x

48 Pillar G, Shehadeh N. Abdominal fat and sleep apnea: the chicken or the egg? Diabetes Care 2008;31:303-309. https://doi.org/10.2337/ $\mathrm{dc} 08$-s 272

49 Fisher D, Pillar G, Malhotra A, et al. Long-term follow-up of untreated patients with sleep apnoea syndrome. Respir Med 2002;96:337343. https://doi.org/10.1053/rmed.2001.1277

50 Sforza E, Addati G, Cirignotta F, et al. Natural evolution of sleep apnoea syndrome: a five year longitudinal study. Eur Respir J 1994 7:1765-1770. https://doi.org/10.1183/09031936.94.07101765

51 Lutter M, Sakata I, Osborne-Lawrence S, et al. The orexigenic hormone ghrelin defends against depressive symptoms of chronic stress. Nat Neurosci 2008;11:752-753. https://doi.org/10.1038/nn.2139

52 Spiegel K, Knutson K, Leproult R, et al. Sleep loss: a novel risk factor for insulin resistance and type 2 diabetes. J Appl Physiol 2005;99:2008-2019. https://doi.org/10.1152/japplphysiol.00660.2005

53 Harsch IA, Schahin SP, Bruckner K, et al. The effect of continuous positive airway pressure treatment on insulin sensitivity in patients with obstructive sleep apnoea syndrome and type 2 diabetes. Respiration 2004;71:252-259. https://doi.org/10.1159/000077423

54 Ip MS, Lam KS, Ho C, et al. Serum leptin and vascular risk factors in obstructive sleep apnea. Chest 2000;118:580-586. https://doi. org/10.1378/chest.118.3.580

55 Conte L, Greco M, Toraldo DM, et al. A review of the "OMICS" for management of patients with obstructive sleep apnoea. Acta Otorhinolaryngol Ital 2020;40:164-172. https://doi. org/10.14639/0392-100X-N0409

56 Lin CC, Wang YP, Lee KS, et al. Effect of uvulopalatopharyngoplasty on leptin and endothelial function in sleep apnea. Ann Otol Rhinol Laryngol 2014;123:40-46. https://doi.org/10.1177/0003489414521385

57 Harsch IA, Konturek PC, Koebnick C, et al. Leptin and ghrelin levels in patients with obstructive sleep apnoea: effect of CPAP treatment. Eur Respir J 2003;22:251-257. https://doi.org/10.1183/09031936.03. 00010103

58 The Report of an American Academy of Sleep Medicine Task Force. Sleep-related breathing disorders in adults: recommendations for syndrome definition and measurement techniques in clinical research. Sleep 1999;22:667-689.

59 Park JG, Ramar K, Olson EJ. Updates on definition, consequences, and management of obstructive sleep apnea. Mayo Clin Proc 2011;86:549-554. https://doi.org/10.4065/mcp.2010.0810

60 Kapur VK, Auckley DH, Chowdhuri S, et al. Clinical practice guideline for diagnostic testing for adult obstructive sleep apnea: an American Academy of Sleep Medicine clinical practice guideline. J Clin Sleep Med 2017;13:479-504. https://doi.org/10.5664/jcsm.6506

61 Basoglu OK, Sarac F, Sarac S, et al. Metabolic syndrome, insulin resistance, fibrinogen, homocysteine, leptin, and C-reactive protein in obese patients with obstructive sleep apnea syndrome. Ann Thorac Med 2011;6:120-125. https://doi.org/10.4103/1817-1737.82440

62 Brodsky L. Modern assessment of tonsils and adenoids. Pediatr Clin North Am 1989;36:1551-1569. https://doi.org/10.1016/ s0031-3955(16)36806-7

63 Netzer N, Eliasson AH, Netzer C, et al. Overnight pulse oximetry for sleep-disordered breathing in adults: a review. Chest 2001;120:625633. https://doi.org/10.1378/chest.120.2.625

64 Salamanca F, Leone F, Bianchi A, et al. Surgical treatment of epiglottis collapse in obstructive sleep apnoea syndrome: epiglottis stiffening operation. Acta Otorhinolaryngol Ital 2019;39:404-408. https:// doi.org/10.14639/0392-100X-N0287
65 Aboussouan LS, Golish JA, Wood BG, et al. Dynamic pharyngoscopy in predicting outcome of uvulopalatopharyngoplasty for moderate and severe obstructive sleep apnea. Chest 1995;107:946-951. https:// doi.org/10.1378/chest.107.4.946

66 Blumen M, Bequignon E, Chabolle F. Drug-induced sleep endoscopy: a new gold standard for evaluating OSAS? Part I: Technique. Eur Ann Otorhinolaryngol Head Neck Dis 2017;134:101-107. https://doi. org/10.1016/j.anorl.2016.11.005

67 Kezirian EJ. Nonresponders to pharyngeal surgery for obstructive sleep apnea: insights from drug-induced sleep endoscopy. Laryngoscope 2011;121:1320-1326. https://doi.org/10.1002/lary.21749

68 Croft CB, Pringle M. Sleep nasendoscopy: a technique of assessment in snoringand obstructive sleep apnoea. Clin Otolaryngol Allied Sci 1991;16:504-509. https://doi.org/10.1111/j.1365-2273.1991. tb01050.x

69 Rabelo FA, Kupper DS, Sander HH, et al. Polysomnographicevaluation of propofol-induced sleep in patients with respiratory sleep disorders and controls. Laryngoscope 2013;123:2300-2305. https://doi. org/10.1002/lary.23664

70 Blumen M, Bequignon E, Chabolle F. Drug-induced sleep endoscopy: a new gold standard for evaluating OSAS? Part II: Results. Eur Ann Otorhinolaryngol Head Neck Dis 2017;134:109-115. https://doi. org/10.1016/j.anorl.2016.12.004

71 Vicini C, De Vito A, Benazzo M, et al. The nose oropharynx hypopharynx and larynx (NOHL) classification: a new system of diagnostic standardized examination for OSAHS patients. Eur Arch Otorhinolaryngol 2012;269:1297-1300. https://doi.org/10.1007/ s00405-012-1965-z

72 Maspero C, Giannini L, Galbiati G, et al. Obstructive sleep apnea syndrome: a literature review. Minerva Stomatol 2015;64:97-109.

73 Cowan DC, Livingston E. Obstructive sleep apnoea syndrome and weight loss: review. Sleep Disord 2012;2012:163296. https://doi. org/10.1155/2012/163296

74 Dobrosielski DA, Papandreou C, Patil SP, et al. Diet and exercise in the management of obstructive sleep apnoea and cardiovascular disease risk. Eur Respir Rev 2017;26:160110. https://doi. org/10.1183/16000617.0110-2016

75 Johansson K, Neovius M, Lagerros YT, et al. Effect of a very low energy diet on moderate and severe obstructive sleep apnoea in obese men: a randomised controlled trial. BMJ 2009;339:b4609. https://doi. org/10.1136/bmj.b4609

76 Vicini C, Colabianchi V, Marrano GG, et al. Description of the relationship between NOHL classification in drug-induced sleep endoscopy and initial AHI in patients with moderate to severe OSAS, and evaluation of the results obtained with oral appliance therapy. Acta Otorhinolaryngol Ital 2020;40:50-56. https://doi. org/10.14639/0392-100X-2290

77 World Health Organization. Obesity: preventing and managing the global epidemic. report of a WHO consultation on obesity. Geneva, Switzerland: World Health Organization; 1998.

78 Kline CE, Crowley EP, Ewing GB, et al. The effect of exercise training on obstructive sleep apnea and sleep quality: a randomized controlled trial. Sleep 2011;34:1631-1640. https://doi.org/10.5665/sleep.1422

79 Netzer N, Lormes W, Giebelhaus V, et al. Physical training of patients with sleep apnea. Pneumologie 1997;51:779-782.

80 Sjöström L, Lindroos AK, Peltonen M, et al. Lifestyle, diabetes, and cardiovascular risk factors 10 years after bariatric surgery. N Engl J Med 2004;351:2683-2693. https://doi.org/10.1056/NEJMoa035622

81 Lettieri CJ, Eliasson AH, Greenburg DL. Persistence of obstructive sleep apnea after surgical weight loss. J Clin Sleep Med 2008;4:333-338. 
82 Pepperell J, Ramdassingh-Dow S, Crosthwaite N, et al. Ambulatory blood pressure after therapeutic and subtherapeutic nasal continuous positive airway pressure for obstructive sleep apnoea: a randomized parallel trial. Lancet 2002;359:204-210. https://doi.org/10.1016/ S0140-6736(02)07445-7

83 Jenkinson C, Davies RJ, Mullins R, et al. Comparison of therapeutic and subtherapeutic nasal continuous positive airway pressure for obstructive sleep apnoea: a randomised prospective parallel trial. Lancet 1999;353:2100-2105. https://doi.org/10.1016/ S0140-6736(98)10532-9

84 Hack M, Davies RJ, Mullins R, et al. Randomised prospective parallel trial of therapeutic versus subtherapeutic nasal continuous positive airway pressure on simulated steering performance in patients with obstructive sleep apnoea. Thorax 2000;55:224-231. https://doi. org/10.1136/thorax.55.3.224

85 Giles TL, Lasserson TJ, Smith BH, et al. Continuous positive airways pressure for obstructive sleep apnoea in adults. Cochrane Database Syst Rev 2006;3:CD001106. https://doi.org/10.1002/14651858. CD001106.pub2

86 McNicholas WT. Compliance with nasal CPAP therapy for obstructive sleep apnoea: how much is enough? Eur Respir J 1997;10:969970. https://doi.org/10.1183/09031936.97.10050969

87 Aarab G, Lobbezoo F, Heymans MW, et al. Long-term follow-up of a randomized controlled trial of oral appliance therapy in obstructive sleep apnea. Respiration 2011;82:162-168. https://doi. org/10.1159/000324580

88 Teixeira AOB, Abi-Ramia LBP, Almeida MAO. Treatment of obstructive sleep apnea with oral appliances. Prog Orthod 2013;14:10. https://doi.org/10.1186/2196-1042-14-10

89 Bishop B, Verrett R, Girvan T. A randomized crossover study comparing two mandibular repositioning appliances for treatment of obstructive sleep apnea. Sleep Breath 2014;18:125-131. https://doi. org/10.1007/s11325-013-0859-7

90 Burlon G, Tepedino M, Laurenziello M, et al. Evaluation of factors that influence the success rate of OSA treatment with a customised adjustable MAD device - a retrospective study. Acta Otorhinolaryngol Ital. 2020;40:297-303. https://doi.org/10.14639/0392-100X-N0307

91 Chaves Junior CM, Dal-Fabbro C, de Bruin VMS, et al. Brazilian consensus of snoring and sleep apnea - aspects of interest for orthodontists. Dental Press J Orthod 2011;16:1-36.
92 Prescinotto R, Haddad FL, Fukuchi I, et al. Impact of upper airway abnormalities on the success and adherence to mandibular advancement device treatment in patients with obstructive sleep apnea syndrome. Braz J Otorhinolaryngol 2015;81:663-670. https://doi.org/10.1016/j. bjorl.2015.08.005

93 Martins OFM, Chaves Junior CM, Rossi RRP, et al. Side effects of mandibular advancement splints for the treatment of snoring and obstructive sleep apnea: a systematic review. Dental Press J Orthod 2018;23:45-54. https://doi.org/10.1590/2177-6709.23.4.045-054.oar

94 Vicini C, Meccariello G, Montevecchi F, et al. Effectiveness of barbed repositioning pharyngoplasty for the treatment of obstructive sleep apnea (OSA): a prospective randomized trial. Sleep Breath 2019;24:687-694. https://doi.org/10.1007/s11325-019-01956-7

95 Mora R, Salzano FA, Mora F, et al. Outcomes of uvulopalatopharyngoplasty with harmonic scalpel after failure of continuous positive airway pressure in sleep apnea syndrome. Acta Otolaryngol 2012;132:299-304. https://doi.org/10.3109/00016489.2011.637178

96 Millman RP, Carlisle CC, Rosenberg C, et al. Simple predictors of uvulopalatopharyngoplasty outcome in the treatment of obstructive sleep apnea. Chest 2000;118:1025-1030. https://doi.org/10.1378/ chest.118.4.1025

97 Iannella G, Vallicelli B, Magliulo G, et al. Long-term subjective outcomes of barbed reposition pharyngoplasty for obstructive sleep apnea syndrome treatment. Int J Environ Res Public Health 2020;17:1542. https://doi.org/10.3390/ijerph17051542

98 Vicini C, Hendawy E, Campanini A, et al. Barbed Reposition Pharyngoplasty (BRP) for OSAHS: a feasibility, safety, efficacy and teachability pilot study. "We are on the giant's shoulders". Eur Arch Otorhinolaryngol 2015;272:3065-3070. https://doi.org/10.1007/ s00405-015-3628-3

99 Montevecchi F, Meccariello G, Firinu E, et al. Prospective multicentre study on barbed reposition pharyngoplasty standing alone or as a part of multilevel surgery for sleep apnoea. Clin Otolaryngol 2018;43:483488. https://doi.org/10.1111/coa.13001

100 Vigneron A, Tamisier R, Orset E, et al. Maxillomandibular advancement for obstructive sleep apnea syndrome treatment: longterm results. J Craniomaxillofac Surg 2017;45:183-191. https://doi. org/10.1016/j.jcms.2016.12.001 